\title{
U.S. PRODUCTIVE CAPACITY: A COMMENT
}

\author{
Pham Chi Thanh
}

I find myself in a somewhat unenviable position. The three papers you heard this morning represent three different approaches to the measurement of U.S. productive capacity. The three conclusions that energed differ quite significantly from one another-amost to the point of being contradictory. It is virtually an tmpossible task as a discussant, therefore, to be nice to all of the authors since if one agrees with one, one will probably have to disagree with another. The easiest way out perhaps is to play the role of a Devil's Advocate to all three papers, and so I will try to catch the Devil by the ideological tail first.

Although the three papers represent three different approaches, it is in the conclusions and their ideological implications that chey differ sharply. George Perry is obviously a liberal Keynesian who shows his concern about the high level of unemployment. To say that there is a large gap between actual output and potential output is to imply that there is room for the government to interfere. Bob Rashe and Jack Tatom are just about at the opposite pole, being conservative. When they show that actual output is only a little below potential and that it will reach its potential maybe within a year, they are trying to sell us the Dr. Thanh is Chairman of the Department of Economics, The American University, washington, D.C. 
idea that no government interference is good interference. "Demand management policies are both unnecessary and inflationary," as they put it. It seems quite strange to hear such an idea expressed so seriously some fifty years after keynes" famous lecture on "The End of Laissez Faire." Peter Clark, on the other hand, seems to have managed to put himself in the middle. I have the impression that he may be a little bit conservative at heart but, being on the staff of the President's Council of Economic Advisers, he cannot very well advocate noninterference by the government.

Haying speculated about the three ideologies, it is probabiy fair to reveal now with whom I side, if only to indicate the line of critique that I an going to deploy. Coming from a radical center like American University, it would seem to be a foregone conciusion. I certainly share George Perry's concern about high unemployment and his belief that the government might be able to interfere to alleviate it, although I do not agree with his approach to the problen of measurement of potential output. From a pure theoretical point of view, Rashe and Tatom's approach is a better one, although there are a number of technical details that I found unsatisfactory. By way of substantiating these remarks, let me begin with some background finst.

To relate a given Jevel of effective demand to a unique volume of employment is one of keynes' famous contributions to short run analysis. This is perfectly legitinate. If the period is sufficiently short, one can reasonably assume that other factors of production are fixed. After al1, the structure of social capital, for example, can only change 
gradually. Thus keynes believes that there exists a level of aggregate effective demand that would generate full utilization of the labor force. Keynes was aware, of course, that even in the short run full employment does not imply a zero rate of unemployment since there will always be frictional and/or voluntary unemployment. On the other hand, to relate a given rate of unemployment to a unique level of aggregate supply is Arthur Okun's contribution (now commonly referred to as Okun's Law), which led to this potential GNP debate. Okun's Law is about the long-run rather than the short-run -.. at least that is how it has been used, with some confusion, in the last fifteen years or so. The general consensus seems to be that, even in the long-run, full utilization of the labor force implies a certain rate of unemployment. This is not a new belief steming from recent revelation. Marx, for example, wrote intensively on the "reserve army of the unemployed" and, in modern times, one often hears the term the "natural" rate of unemployment from a conservative like Milton Friedman as well as from a liberal Tike Edmund Phelps. Indeed, no rate of unemployment in the short run can be regarded as "natural" by anyone in any sense.

Almost everyone seems to subscribe to the view that in the long run there is a mininum rate of unemployment that can not be reduced permanently by fiscal or monetary measures. This is the so-called "benchmark" unemployment rate. The obvious initial confusion was that it was measured by the simple head count, which is appropriate only in the short run. This is because unemployment, like sickness, takes its toll in a 11 age groups and in both sexes. For some reason, certain 
groups like female and young males, particularly black, are more susceptible to the disease than others. It follows, therefore, if the composition of the labor force changes, the benchmark rate will change accordingly. George Perry's ingenious device of unemployment weights is well-known and addresses itself directly to the long-run measure of the benchmark rate. In this respect, Peter Clark's work on labor force and participation rates also deserves praise. The only thing that I am unhappy about is the easy and convenient reference to "cyclical variations" and "trend break." of course, they are necessary to suit their econometrics but these do not provide an explanation. To give an example, Perry's 1967 trend break happens to coincide with a remarkable phenomenon. Beginning in about 1966, the hourly wage of unskilled and semi-skilled workers falls relatively to the hourly wages of skilled workers. This was also the beginning of a period of expansion by U.S. multinational firms. They started to move their labor-intensive processes of production abroad where unskilled and semi-skilled labor was cheaper than in the U.S. One can imagine that a great proportion of females and young males, who were new in the labor market, belonged to this unskilled and semi-skilled category. To emphasize the point more strongly, one could say that the largest 500 firms in the U.S. can provide the same level of output with significantly less manpower by moving some of their production away from the U.S. and then importing these goods back to the home market. That is why Peter CTark's exclusion of "output generated from the rest of the world," which seems perfectly reasonable and innocent on the surface, might have an important bearing 
on domestic output and the actual volume of employment. It would be nice to know how much of the "output generated from the rest of the world" was actually produced by U.S. multinational corporations.

Now, since all authors in their revision of the Council of Economic Advisers' early estimates of potential GNP have looked upon the benchmark unemployment rate as a long-run concept, they a11 naturally extend their analyses to take account of other factors of production such as capital and energy resource. Everyone knows that the presence of capthal input will pose great difficulty. Even in pure theory, the capital problem has never been quite settied. When one wants to deal with it econometrically it is a real headache and I can sympathize with George Perry's complaint. Unlike non-durable goods which can be handled with the help of an index, the evaluation of capital involves not only a cross-section index but also one that involves time itself. A new airplane is as different from an old airplane as it is from a new motor car. Strictly speaking, however, the evaluation of capital is no more complicated than the evaluation of labor. Perry wonders how are we to measure the flow of the productive services from a machine since, without incurring any new investment, we can expand its productivity by extending the number of hours it is used. Wel1, the same applies to a worker. The flow of productive services from a worker can always be expanded by making him or her work longer hours rather than adding an extra person to the labor force.

Although Peter Clark and Rashe and Tatom recognize the difficulty, they brave a try at the capital stock. The strange thing is that they 
pay so much attention to obtaining a measure of the labor force and unemployment that is better than the simple head count, but did not do the same with respect to capital stock. Just as the simple head count will give a wrong picture of labor input and unemployment, counting machines will give a wrong picture of capital input. Indeed, as far as capital stock is concerned, it is very important to know the composition of social capital, and the average life of plants and capital equipment as well as the rate of accumulation. Any change in these will affect the volume of output produced, and therefore the relationship between output and labor utilization.

Knowledge of the rate of accumulation is of particular importance when energy resource is recognized as another factor of production. Even in the theoretical literature the introduction of an exhaustible resource, such as energy, into the analysis of growth is a new thing. 1 applaud Rashe and Tatom's effort in incorporating this into their estimate of potential output. Their use of a Cobb-Douglas production function is however unfortunate. While there are good reasons in the theoretical literature for the use of a Cobb-Douglas production function, there is no compelling reason for using it here. This particular production function is used in the theoretical literature because it is the best weapon to defend growth theory. Two of the special properties of the Cobb-Douglas production function are that (i) output falls to zero whenever one input falis to zero so that every input is essential and (ii) the Average Product and Marginal Product of every input goes to infinity as the input falls to zero. Unless we make such assumptions, 
there cannot be any economic growth when exhaustible resource is a factor of production if the stock of resource is finite and if its average product is unbound only a finite quantity of output can ever be produced. Therefore if growth is to be possible, this must not happen. But that is the theoretical literature, where one is at liberty to make any assumption to suit one's Tine of defense. For the problem at hand, the use of a Cobb-Douglas functon, besides its usual distorted picture of production, involves also the implication of infinite substitution possibility between energy and other input. If the price of one input rises relative to another, we substitute. Well, the concept of substitution at the macro level in economics is a strange one. It is like a beautiful woman, always being loved and always being misunderstood. Substitution in the macroeconomic sense does not mean input can always be immediately transformed. A drastic fall in wage rate today does not mean that each Greyhound bus from Chicago to St. Louts wi1l now be driven by ten drivers. A drastic rise in the price of fuet does not mean that the bus will be pushed ly drivers to $5 t$. Louis all the way from Chicago. Substitution in the macro sense must be understood as scrapping old equipment and reptacing it with new, accompanied by a different labor intensity and/or different fuel consumption. Very high fuel cost will lead to the production of new cars which consume less gas. In other words, it takes time and needs the help of technical progress. In using a Cobb-Douglas production functon, Rashe and Tatom make the same spectification error as the followers of Solow made more than a decade ago. The elasticities $\alpha, \beta$ and $\gamma$ in their paper are the 
so-called "surrogate" elasticities. They do not tell us about the relative shares nor do they give any information about the production process. Therefore, the calculation of potential output based on such a function is quite futile. Their estimate of demand for energy is based on the assumption that energy will always be used, up to the point where the value of its marginal product is equated to its price. Beside the implication of instant substitution that I mentioned earlier, this assumption also carries another extraordinary implication. Their estimated value of the output elasticity for energy is $9.4 \%$ which implies that the share of energy factor in the U.S. national income is almost $10 \%$ !

Earlier, I said that the knowledge of the rate of saving is of particular importance when energy resource is recognized as another factor of production. If income is to grow steadily, then the rate of saving affects not only the rate of growth but also the level of output produced. Rasche and Tatom's calculation of growth rate of $3 \%$ is therefore more of a wild guess than a meaningful estimate.

In general, I think it is possible to estimate potential output, which corresponds to given levels of input utilization. But to do so, one needs to be able to estimate capital stock and energy resource utilization correctly. The three papers do not give satisfactory calculations in this respect. From a more general viewpoint, I also think the debate misses a fundamental point. Everyone obviously likes to see a lower rate of unemployment and it may be possible to reduce it to a long run minimum rate by expanding output. But this is a shortsighted 
View. Faster growh rate or hoher production also means using up exhaustible resources at a faster rate. A wrong choice may mean drying up resources at a potnt in the that we canot afford to do so. The problen is not a simple tradem of like the inflation-unemployment, crade-off of the good old days of the phllips curve. It is more like a trade-oft between low unemployment now and high unemployment later or melative abundance now and poverty tater. The chotce involves future generathon yet. to be born and therefore, no social contract

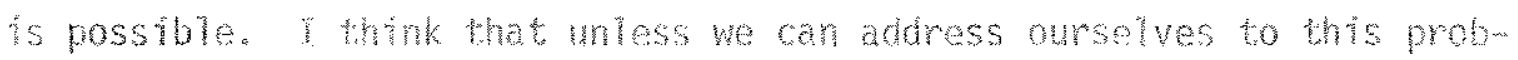
lem, the estomation of potontha oup or henchark unemployment mate does not have moh maning beyond an intellectual axemos. 